\title{
A Comparison of Feeding Multi-Probiotics and Fermented Ginseng Byproducts on Performance, Intestinal Microflora and Immunity of Broiler Chicks
}

\author{
Md. Rakibul Hassan ${ }^{1}$, Ho Sung Choe ${ }^{2}$ and Kyeong Seon Ryu ${ }^{1,+}$ \\ ${ }^{I}$ Department of Animal Science, Chonbuk National University, Jeonju 561-756, Republic of Korea \\ ${ }^{2}$ Department of Animal Biotechnology, Chonbuk National University, Jeonju 561-756, Republic of Korea
}

\begin{abstract}
This study was undertaken to investigate the influence of multi-probiotics, fermented ginseng byproducts and fermented sulfone as an alternative to probiotics on performance, intestinal microflora and immunity of broiler. A five weeks trial was conducted with one day old Ross $\times$ Ross broilers $(n=340)$, divided into five groups which further divided into 4 replicates with 17 birds in each replicate. Birds were assigned to 5 dietary treatments as control, antibiotic avilamycin (AB), multi-probiotics (MP), fermented sulfone (FS) and fermented ginseng byproducts (FGB). Growth parameters were recorded on weekly basis while rest of the parameters viz. blood and faeces were collected at the end of the experiment. Growth parameters were not affected statistically by dietary treatments. However, numerically, higher body weight, splenocytes proliferation and lower total cholesterol and LDL values were found in MP treatment $(P>0.05)$. Salmonella spp. count $(P \leq 0.001)$ and $E$. coli $(P<0.001)$ concentrations in the ileum were found lowest in $\mathrm{AB}$ treatment while $\mathrm{FS}$ group showed lowest level of yeast $(P<0.10)$ and Lactobacillus spp. $(P \leq 0.001)$. Fecal ammonia and $\mathrm{CO}_{2}$ emission was significantly decreased in FGB than other dietary treatments $(P<0.05)$. It was concluded that multi-probiotics would be valuable feed additives to improve the growth performance, Lactobacillus proliferation and immunity of broiler chicks.
\end{abstract}

(Key words : multi-probiotic, fermented ginseng by-products, Lactobacillus, splenocyte, broiler)

\section{INTRODUCTION}

The use of antibiotics and other antimicrobials has been practiced for many years to enhance growth performance, disease prevention and efficient use of feeds in livestock feed industry (Barton, 2000). At present, a large number of natural growth promoters are commercially available including probiotics, prebiotics and immune modulators. These products have the potential to influence the intestinal tract in a positive way thus, improving the health, well-being and performance of animals (Fuller, 1989). Antibiotic feed additives as growth promoters have long been supplemented to poultry feed to stabilize the microbial flora and improve the general performances and prevent some specific intestinal pathogens (Waldroup et al., 2003). However the antibiotic growth promoters have been under scrutiny for many years and have been removed from the market in many countries (Ratcliff, 2000). The inclusion of antibiotics in the diets of animal has been prohibited in the EU countries since January 2006. In Korea, since July 2011, complete ban in the use of antibiotics as a growth promoter in animal feed has been come in to picture to ensure the safety of livestock products for consumers. Therefore, it is necessitated to find effective alternatives to antibiotic feed ingredients as prophylactic antibacterial and growth promoters. Feed additives such as enzymes, herbal products, microflora enhancers, immunomodulators, organic acids, probiotics, prebiotics or combinations of these products are being used as an alternative to antibiotics in poultry diet. Probiotics are being considered to fill this gap and already some farmers are using them (Trafalska and Grzybowska, 2004). There is sufficient evidence to show that probiotics are effective in enhancing the immune system, increasing body weight gain, reducing diarrhea and improving feed conversion efficiency (Patterson and Burholder, 2003). Several authors (Tortuero, 1973; Jin et al., 1998; Kalavathy et al., 2003; Mountzouris et al., 2007) found that probiotic species belonging to Lactobacillus, Streptococcus, Bacillus, Bifidobacterium, Enterococcus, Aspergillus, Candida, and Saccharomyces have a beneficial effect on broiler performance but limited infor-

\footnotetext{
${ }^{\dagger}$ To whom correspondence should be addressed : seon@jbnu.ac.kr
} 
mation is available regarding the effect of multi-probiotics, fermented ginseng byproducts and sulfone as probiotics on broiler. Therefore, this study was undertaken to investigate the feeding of multi-probiotics, fermented ginseng byproducts and fermented sulfone on the performance, blood composition, intestinal microflora, noxious gas emission and immunity of broiler chicks.

\section{MATERIALS AND METHODS}

\section{Birds and Dietary Treatments}

Day old Ross $\times$ Ross broiler chicks $(n=340)$ were obtained from a commercial hatchery and divided in to five groups. Each group had four replicates with 17 birds in each. Five corn-soybean based dietary treatments were formulated to meet Ross $\times$ Ross broiler nutrient requirements for starter ( 1 to $21 \mathrm{~d})$ and finisher $(22 \sim 35 \mathrm{~d})$ period. Control or basal with crude protein (CP) 22 and $20 \%$ was provided for starter and finisher phases, respectively, and metabolizable energy was (ME) $3,100 \mathrm{kcal} / \mathrm{kg}$. All diets were formulated to meet or exceed the nutrient requirements of broiler chickens (NRC, 1994) (Table 1). In $2^{\text {nd }}, 3^{\text {rd }}, 4^{\text {th }}$ and $5^{\text {th }}$ diet antibiotic avilamycin ( $\mathrm{AB}$ ), multi-probiotics (MP), fermented sulfone (FS) and fermented ginseng byproducts (FGB) was inoculated with $0.1 \%$ level to basal diet, respectively. The experimental duration was for 5 weeks. All the chicks were provided clean floor pen and rice hulls as litter. Throughout the experimental period the diet and water were supplied ad libitum to birds with $24 \mathrm{~h}$ access to lighting.

\section{Preparation of Feed Additives}

The probiotics products used in the experiment were supplied by TJ Bio Company, Republic of Korea. In the present experiment, avilamycin was used as an antibiotic (AB). Multiprobiotics (MP) was comprised of Lactobacillus plantarum $\left(5 \times 10^{7} \mathrm{cfu} / \mathrm{g}\right)$, Saccharomyces cerevisiae $\left(6 \times 10^{7} \mathrm{cfu} / \mathrm{g}\right)$ and Bacillus subtillis, $\left(2 \times 10^{7} \mathrm{cfu} / \mathrm{g}\right)$. Fermented sulfur (FS) was prepared by fermenting mixed processed sulfur, gluten and Bacillus subtillis $\left(2 \times 10^{7} \mathrm{cfu} / \mathrm{g}\right)$ at the room temperature. Same procedure was applied to prepare fermented ginseng byproducts (FGB) wherein processed sulphur was replaced by ginseng byproduct.
Table 1. Composition and nutrition analysis of experimental diets

\begin{tabular}{|c|c|c|}
\hline \multirow{2}{*}{ Ingredients } & Starter & Finisher \\
\hline & \multicolumn{2}{|c|}{$(\%)$} \\
\hline Corn & 54.88 & 60.10 \\
\hline Soybean meal & 32.60 & 30.88 \\
\hline Corn gluten meal & 4.71 & 2.10 \\
\hline Soybean meal oil & 4.00 & 3.70 \\
\hline Lime stone & 1.32 & 1.44 \\
\hline Di calcium phosphate & 1.73 & 1.14 \\
\hline Salt & 0.40 & 0.40 \\
\hline L-Lysine & 0.03 & - \\
\hline DL-Methionine & 0.13 & 0.04 \\
\hline Vitamin premix ${ }^{1}$ & 0.10 & 0.10 \\
\hline Mineral premix ${ }^{2}$ & 0.10 & 0.10 \\
\hline Total & ----------- & --------- \\
\hline \multicolumn{3}{|l|}{ Calculated value } \\
\hline Metabolizable energy (kcal/kg) & 3,100 & 3,100 \\
\hline Crude protein $(\%)$ & 22.00 & 20.00 \\
\hline Lysine (\%) & 1.10 & 1.00 \\
\hline Methionine (\%) & 0.50 & 0.38 \\
\hline $\mathrm{Ca}(\%)$ & 1.00 & 0.90 \\
\hline Available phosphate (\%) & 0.45 & 0.35 \\
\hline
\end{tabular}

${ }^{1}$ Contain per kg: vit. A, $12,000 \mathrm{IU}$; vit $\mathrm{D}_{3}, 5,000 \mathrm{IU}$; vit E, $50 \mathrm{mg}$; vit $\mathrm{K}_{3}, 3 \mathrm{mg}$; vit $\mathrm{B}_{1}, 2 \mathrm{mg}$; vit $\mathrm{B}_{2}, 6 \mathrm{mg}$; vit $\mathrm{B}_{6}, 4 \mathrm{mg}$; vit $\mathrm{B}_{12}$, $25 \mathrm{mg}$; biotin, $0.15 \mathrm{mg}$; pantothenic acid, $20 \mathrm{mg}$; folic acid, 2 $\mathrm{mg}$; nicotinic acid, $70 \mathrm{mg}$.

${ }^{2}$ Contain per kg: Fe, $66.72 \mathrm{mg}$; Cu, $41.70 \mathrm{mg}$; Mn, $83.40 \mathrm{mg}$; $\mathrm{Zn}, 66.72 \mathrm{mg}$; I, $0.834 \mathrm{mg}$; Se, $0.25 \mathrm{mg}$.

\section{Data Collection}

\section{1) Performance Parameter}

Body weight $(\mathrm{g})$ of chickens in each pen was measured weekly to determine average body weight and weight gain. The feed intake (feed consumption, g) of birds per pen was recorded weekly and the feed conversion ratio of each pen was calculated [feed conversion ratio $=$ feed intake $(\mathrm{g}) /$ net gain of body weight $(\mathrm{g})]$. 


\section{2) Lipid Characteristic in Blood}

At the end of feeding trail ten birds per treatment were kept for twenty four hours fasting. Blood samples were collected from the branchial vein and kept in a vacuum tube. Twelve hours after collection, the serum was separated and stored at $-70^{\circ} \mathrm{C}$ until analysis. The total cholesterol, triglyceride, HDL and LDL-cholesterol concentration in blood were measured by using test kit by enzymatic colorimetric method (AM 202-K; Asan Pharm Co., LTD, Korea).

\section{3) Intestinal Microorganism}

At 35 days of age, three broilers per treatment were killed and the carcasses were subsequently opened to collect the fecal sample from the ileum. One gram of collected sample was diluted with $10 \mathrm{~mL}$ of sterilized $9 \%$ saline solution (Joongwae Pharmaceutical Co., LTD, Korea), out of which $1 \mathrm{~mL}$ was transferred into $9 \mathrm{~mL}$ of the sterilized saline solution. Samples were serially diluted from $10^{-1}$ to $10^{-6}$, and were injected by $100 \mu \mathrm{L}$ in medium. Salmonella, E coli, yeast and Lactobacillus spp. were enumerated using SS agar, MacConkey agar, Yeast morphology agar and Rogosa agar of Difco (USA). Plates were then incubated at $37^{\circ} \mathrm{C}$ for $24 \mathrm{~h}$ aerobically (SS, MacConkey and Yeast morphology agar) or 48 anaerobically (Rogosa agar) colonies so developed were counted and the result showed as colony-forming unit $\log 10$ per gram of sample.

\section{4) Gas Emission of Feces}

At the end of feeding trial, three broilers from each treatment were randomly selected and were allotted to individual cage. After three days adapting period, $50 \mathrm{~g}$ of feces were collected and kept in a 1,000 $\mathrm{mL}$ glass container and subsequently capped by parafilm. The containers were then stored for $5 \mathrm{~min}$ at room temperature. The $\mathrm{NH}_{3}$ and $\mathrm{CO}_{2}$ concentration were measured by using Gastec (GV-100, Japan).

\section{5) Proliferation of Splenocyte}

Three broilers per treatment at the age of 35 days were killed by severing the jugular vein and spleen was isolated. The acquired sample was kept separate and was dissociated between the frosted ends of two microscope slides. Erythrocytes were lysed in $\mathrm{RBC}$ lysis buffer for $5 \mathrm{~min}$ at room temperature and spun at $1,500 \mathrm{rpm}$ for $5 \mathrm{~min}$. The splenocytes was washed two times with DMEM (Dulbecco's Modified Eagle Medium) and were cultured at a density of $10^{6}$ cells $/ \mathrm{mL}$. The cells were cultured at $37^{\circ} \mathrm{C}$ and $5 \% \mathrm{CO}_{2}$ in DMEM containing 10\% fetal bovine serum (FBS; Sigma-Aldrich, St. Louis, MO) and antibiotics for $48 \mathrm{~h}$. Cell proliferation was determined by the 3-(4,5-dimethylthiazol-2-yl)-5-(3-carboxymethoxyphenyl)-2-(4-sulfophenyl)-2H-tetrazolium MTS) assay (Buttke et al., 1993), using a Cell Titer 96 aqueous non-radioactive cell proliferation assay kit (Promega, Madison, WI). Absorbance was measured using a microplate reader at $490 \mathrm{~nm}$.

\section{6) Statistical Analysis}

Analysis of variance (ANOVA) using GLM procedure of SAS (1998) was used to analyze the data. The difference among treatments was determined with Duncan's new multiple range test (Steel and Torrie, 1980) and significance was declared when the probability was less than $5 \%(P<0.05)$.

\section{RESULTS AND DISCUSSION}

In the present experiment no significant difference in broiler growth performance from 1 to 35 days of age was evident (Table 2), however numerically higher body weight and improved FCR was obtained from the broilers fed MP diets. The improvement of body weight gain of broiler fed MP might be due to the Lactobacillus spp. used in the supplement which colonize in the gastrointestinal tract and improve the digestibility of nutrients in the ileum (Pelicia et al., 2004), which agrees with the present findings. In addition, probiotics suppresses the growth of pathogenic microorganisms in the intestine and have potential to increase the bioavailability of dietary minerals resulting in an improved growth rate and feed efficiency (Toghyani et al., 2011). In contrast, with the present results, several workers (Watkins and Kratzer, 1984; Maiolino et al., 1992) reported that there were no significant differences in weight gain of chicken given diets with or without Lactobacillus cultures. Another group of researcher reported that the inoculation of probiotics has no effect on weight gains (Midilli et al., 2008; Alp et al., 1993) and feed consumption (Cavit, 2004; Yalcinkayal et al., 2008) but small improvements in efficiency (Mohan et al., 1996, Tortuero, 1973). 
Table 2. Effect of feeding probiotics on the performance of broiler chicks

\begin{tabular}{lccccccc}
\hline \hline \multirow{2}{*}{ Item } & \multicolumn{5}{c}{ Treatments } \\
\cline { 2 - 7 } & Control & AB & MP & FS & FGB & SEM & $P$-value \\
\hline Weight gain (g) & 1,639 & 1,744 & 1,766 & 1,720 & 1,708 & 22.80 & 0.53 \\
Feed intake (g) & 2,771 & 2,798 & 2,900 & 2,913 & 2,873 & 30.33 & 0.14 \\
FCR & 1.698 & 1.605 & 1.643 & 1.703 & 1.682 & 0.02 & 0.94 \\
TCL (mg/dL) & 97.14 & 110.42 & 98.85 & 103.85 & 102.00 & 2.94 & 0.67 \\
TG (mg/dL) & 18.14 & 21.85 & 17.71 & 22.43 & 25.85 & 1.11 & 0.12 \\
HDL (mg/dL) & 74.71 & 86.57 & 76.71 & 81.57 & 83.28 & 2.96 & 0.73 \\
LDL (mg/dL) & 18.80 & 19.48 & 18.57 & 17.80 & 13.54 & 1.00 \\
\hline
\end{tabular}

SEM-Standard error of mean; AB, antibiotics; MP, mutiprobiotics; FS, fermented sulfone; FGB, fermented ginseng byproducts; FCR-feed conversion ratio; TCL-total cholesterol; TG-tri-glyceride ; HDL-high density lipoprotein; LDL-low density Lipoprotein.

Jin et al. (1996a) showed that an increase $(P<0.05)$ in body weight gain and feed efficiency of broilers $(P<0.05)$ when $B$. subtilis and Lactobacilli cultures were added to their diets. Kermanshahi and Rostami (2006) and Thitaram et al. (2005) reported that probiotics can improve the weight of birds. Thus, the variation of broilers performance to the microbial products might be due to the variation of microbial culture used in the probiotics, application level, feed composition, age and strain of the bird.

In present study, numerically lower level of triglyceride and LDL content was found in MP treatment but total cholesterol and HDL content was higher in $\mathrm{AB}$ and lower in control group (Table 2). It is noteworthy that a non significant reduction of serum cholesterol level $(97.14 \mathrm{mg} / \mathrm{dL})$ was found in control group. This value is similar to the mean value of $98.85 \mathrm{mg} / \mathrm{dL}$ cholesterol value obtained from MP supplemented group. The present finding is in line with (Djouvinov et al., 2005) who stated that the probiotic supplementation did not significantly affect the level of total cholesterol level in the broiler serum. In contrast, the addition of 0.05 and $0.1 \%$ Lactobacillus cultures to feed led to significant reduction of cholesterol levels in the serum of broilers (Jin et al., 1998). Similar depressing effect of probiotics on serum cholesterol concentrations has been found in broilers (Mohan et al., 1996). The decrease in cholesterol level could be due to cholesterol assimilation by the Lactobacillus cells (Gilliland et al., 1985), or to the co-precipitation of cholesterol with deconjugated bile salts (Klaver and Van der Meer, 1993) and reduction of $\mathrm{pH}$ in the intestinal tract, can be effective in reducing the cholesterol.

The composition of microflora in illeal intestine is presented in Table 3. There was significant difference $(P<0.05)$ in Salmonella, E. coli and Lactobacillus spp. populations due to dietary treatments. The illeal micro flora concentration of Salmonella and E. coli were found significantly $(P<0.05)$ higher in control group. On the other hand, Salmonella concentration was remarkably $(P<0.05)$ lower in antibiotic $(\mathrm{AB})$ treatment, whereas MP, FS and FGB were intermediate and not different from each other. This might be due to the inoculation of $B$. subtilis culture in diet which favored the numbers of natural Lactobacillus and suppress E. coli in the gut wall. The Lactobacillus concentration in the ileum was also influenced $(P<0.05)$ by the treatments where highest proliferation belongs to MP group whereas control and antibiotics were the moderate and FS showed the lowest proliferation. The Lactobacillus spp. used in the present study have a strong ability to attach to the intestinal epithelium of chicken, which are resistant to the bile and acidic conditions and are able to antagonize and competitively exclude some pathogenic bacteria in vitro (Jin et al., 1996b). In contrast, yeast population remained unaffected due to any dietary treatment; however a numerically higher value was obtained in control diet. Recently, Falaki et al. (2011) found E. coli have reduced the growth of poultry due to toxin production and 
Table 3. Effect of feeding probiotics on ileal microbes of broiler chicks

\begin{tabular}{lccccccc}
\hline \hline \multirow{2}{*}{ Item } & \multicolumn{3}{c}{ Treatments } \\
\cline { 2 - 8 } & Control & AB & MP & FS & FGB & SEM & $P$-value \\
\hline Salmonella $\left(\log _{10} \mathrm{cfu} / \mathrm{g}\right)$ & $5.18^{\mathrm{a}}$ & $3.48^{\mathrm{c}}$ & $4.41^{\mathrm{b}}$ & $4.36^{\mathrm{b}}$ & $4.56^{\mathrm{b}}$ & 0.14 & 0.001 \\
E. coli $\left(\log _{10} \mathrm{cfu} / \mathrm{g}\right)$ & $6.99^{\mathrm{a}}$ & $5.07^{\mathrm{b}}$ & $5.17^{\mathrm{b}}$ & $5.16^{\mathrm{b}}$ & $5.35^{\mathrm{b}}$ & 0.19 & 0.003 \\
Yeast $\left(\log _{10} \mathrm{cfu} / \mathrm{g}\right)$ & 6.24 & 4.94 & 5.91 & 4.90 & 5.85 & 0.21 & 0.07 \\
Lactobacillus spp. $\left(\log _{10} \mathrm{cfu} / \mathrm{g}\right)$ & $6.89^{\mathrm{bc}}$ & $6.99^{\mathrm{bc}}$ & $8.03^{\mathrm{a}}$ & $6.65^{\mathrm{c}}$ & $7.39^{\mathrm{b}}$ & 0.13 & 0.001 \\
\hline
\end{tabular}

a-c Value with a row with no common superscripts differ significantly $(P<0.05)$. AB, antibiotics; MP, mutiprobiotics; FS, fermented sulfone; FGB, fermented ginseng byproducts.

utilization of nutrients essential to the host and suppression of microbes that synthesize vitamins and other host growth factor. In the ileum, populations of useful bacteria like Lactobacillus and Bifidobacteria (Ziggers, 2000) increases with the increase in $\mathrm{pH}$ of GIT which increases the production of volatile fatty acids. Therefore, the environment of GIT becomes unsuitable for the activity and proliferation of pathogens like Salmonella. In case of turkey, ingestion of $B$. subtilis culture had no significant effect on the Lactobacillus and E. coli populations in intestine (Saarchit and Sullivan, 1990). Other studies have also demonstrated the potential of probiotics to fortify the intestinal microflora of broiler chickens with beneficial bacteria and suppress potentially pathogenic bacteria (Koenen et al., 2004; Teo and Tan, 2007; Higgins et al., 2007).

Furthermore, fecal ammonia and $\mathrm{CO}_{2}$ emission was significantly $(P<0.05)$ decreased in MP, FGB and FS group (Table 4). Highest concentration of ammonia was found in control group which considerably reduced in FGB group whereas MP and FS group had an intermediated effect on $\mathrm{NH}_{3}$ emission. Similarly, lowest $(P<0.05)$ fecal $\mathrm{CO}_{2}$ concentration was found in FGB treatment. The possible mechanism might be feeding of MP released digestive enzymes and thus increases nitrogen availability and nutrient digestibility in the intestine, the impact was reflected on the concentration of $\mathrm{NH}_{3}$ and $\mathrm{CO}_{2}$ in the feces (Yoon et al., 2004). In another study, it was mentioned that supplementation of probiotics significantly $(P<$ 0.05 ) decreased the fecal $\mathrm{NH}_{3}$ and non-significantly reduced $\mathrm{CO}_{2}$ gas emission in broiler, (Yoon et al., 2004). The present finding is in line with Lee et al. (2006) and Kim et al. (2003) reported that probiotics supplementation decreased the ammonia gas production in broiler.

A significantly higher $(P<0.05)$ splenocytes proliferation was found in MP and control group (Fig. 1) which resulted in the increase in spleen lymphoid cell number. The enlargement of the spleen might be due to the microbial populations balance in the digestive tract. No significant difference was found among MP, control, AB and FGB group, however significantly $(P<0.05)$ lower splenocyte proliferation was found in FS treated group. In meat-type strains, Lactobacilli did not influence the non-specific proliferative response of isolated spleen cells (Koenen et al., 2004) but immunoprobiotic Lactobacilli might enhance disease resistance which agrees the present findings. In another experiment, Clancy (2003) descri-

Table 4. Effect of feeding probiotics on noxious gas emission in broiler manure

\begin{tabular}{cccccccc}
\hline \hline \multirow{2}{*}{ Item } & \multicolumn{5}{c}{ Treatments } \\
\cline { 2 - 7 } & Control & $\mathrm{AB}$ & $\mathrm{MP}$ & $\mathrm{FS}$ & FGB & SEM & $P$-value \\
\hline $\mathrm{NH}_{3}(\mathrm{ppm})$ & $72^{\mathrm{a}}$ & $52^{\mathrm{ab}}$ & $37^{\mathrm{bc}}$ & $29^{\mathrm{bc}}$ & $14^{\mathrm{c}}$ & 5.51 & 0.001 \\
$\mathrm{CO}_{2}(\mathrm{ppm})$ & $1,733^{\mathrm{a}}$ & $966^{\mathrm{b}}$ & $933^{\mathrm{b}}$ & $933^{\mathrm{b}}$ & $767^{\mathrm{b}}$ & 113.94 & 0.03 \\
\hline
\end{tabular}

${ }^{\mathrm{a}-\mathrm{c}}$ Means in the same column for each parameter with different superscripts are significantly different $(P<0.05)$. $\mathrm{AB}$, antibiotics; MP, mutiprobiotics; FS, fermented sulfone; FGB, fermented ginseng byproducts. 


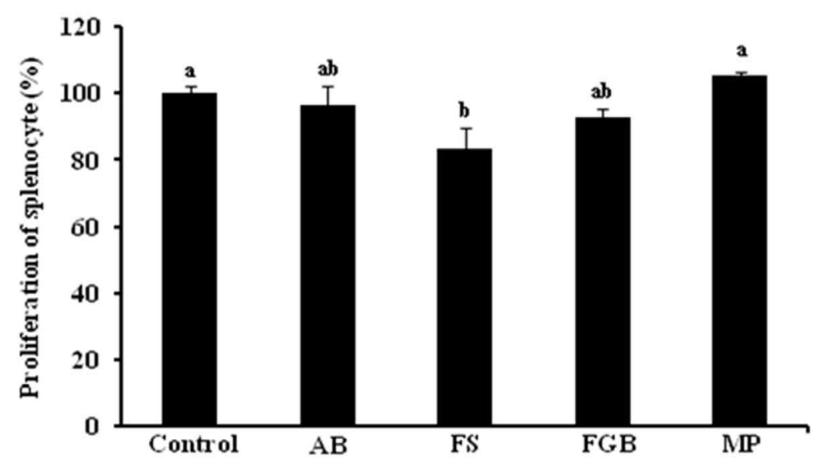

Fig. 1. Effect of feeding probiotics on proliferation of spleen in broiler. $\mathrm{AB}$, antibiotics; MP, mutiprobiotics; FS, fermented sulfone; FGB, fermented ginseng byproducts.

bed that probiotic bacteria activate dendritic cells in Peyers' patches which in turn stimulate the T-lymphocytes. In this way these T-cells might also exert their immune modulation at distant mucosal sites. As more Lactobacilli reached the Peyers' patches they would activate more dendritic cells and indirectly increase the immune response.

\section{CONCLUSION}

In conclusion, multi-probiotics increased the body weight and decreases the triglyceride and LDL level in the blood. It also increases the concentrations of Lactobacillus and decreases the pathogenic organisms in the ileum. Higher proliferation of splenocyte was attained by feeding of multi-probiotics. Therefore, multi-probiotics would be valuable feed additives to improve the growth performance, lactobacillus proliferation and immunity of broiler chicks.

\section{LITERATURE CITED}

Alp M, Kahraman R, Kocabağli N, Eren M, Şenel SH 1993

The effects of lactiferm-15 and some antibiotics on performance, abdominal fat, intestinal tract weight and blood cholesterol levels of broilers. Vet J Istanbul Univ 19: 145-157.

Barton MD 2000 Antibiotic use in animal feed and its impact on human health. Nutr Res Rev 13:279-299.

Buttke TM, McCubrey JA, Owen TC 1993 Use of an aqueous soluble tetrazolium/formazan assay to measure viability and proliferation of lymphokine-dependent cell lines. J Immunol Methods 157:233-240.

Cavit A 2004 Effect of dietary probiotic supplementation on growth performance in the rock patridge (Alectoris gracea). Turk J Vet Anim Sci 28:887-891.

Clancy R 2003 Immunobiotics and the probiotic evolution. FEMS Immunol and Med Microbiol 38:9-12.

Djouvinov D, Boicheva S, Simeonova T, Vlaikova T 2005 Effect of feeding lactina probiotic on performance, some blood parameters and caecal microflora of mule ducklings. Trak J Sci 3:22-28.

Falaki M, Shargh MS, Dastar B, Zerehdaran S, Khomairi M 2011 The investigation of intestinal microflora and growth response of young broilers given feed supplemented with different levels of probiotic and prebiotic. J Anim Vet Advances 10:385-390.

Fuller R 1989 A review: Probiotics in man and animals. J Applied Microbiol 66:365-378.

Gilliland SE, Nelson CR, Maxwell C 1985 Assimilation of cholesterol by Lactobacillus acidophilus. Appl Environ Microbiol 49:377-381.

Higgins JP, Higgins SE, Vicente JL, Wolfenden AD, Tellez G, Hargis BM 2007 Temporal effects of lactic acid bacteria probiotic culture on Salmonella in neonatal broilers. Poultry Sci 86:1662-1666.

Jin, LZ, Ho YW, Abdullah N, Jalaludin S 1996a Influence of dried Bacillus subtilis and Lactobacilli cultures on intestinal microflora and performance in broilers. Asian-Aust $\mathrm{J}$ Anim Sci 9:397-404.

Jin, LZ, Ho YW, Ali MA, Abdullah N, Jalaludin S 1996b Effect of adherent Lactobacillus spp. on in vitro adherence on Salmonellae to the intestinal epithelial cells of chickens. J Appl Bacteriol 81:201-206.

Jin LZ, Ho YW, Abdullah N, Jalaludin S 1998 Growth performance, intestinal microbial populations and serum cholesterol of broilers fed diets containing Lactobacillus cultures. Poultry Sci 77:1259-1265.

Kalavathy R, Abdullah N, Jalaludin S, Ho YW 2003 Effects of Lactobacillus cultures on growth performance, abdominal fat deposition, serum lipids and weight of organs of broiler chickens. Br Poult Sci 44:139-144.

Kim SH, Park SY, Yu DJ, Lee SJ, Ryu KS, Lee DG 2003 
Effects of feeding Aspergillus oryzae ferments on performance, intestinal microflora, blood serum components and environmental factors in broiler. Kor J Poult Sci 30:151159.

Kermanshahi H, Rostami H 2006 Influence of supplemental dried whey on broiler performance and cecal flora. Int J Poult Sci 5:538-543.

Klaver FAM, Van der Meer R 1993 The assumed assimilation of cholesterol by Lactobacilli and Bifidobacterium bifidium is due to their bile salt-deconjugating activity. Appl Environm Microbiol 59:1120-1124.

Koenen ME, Kramer J, van der Hulst R, Heres L, Jeurissen SHM, Boersma WJA 2004 Immunomodulation by Probiotic lactobacilli in layer and meat-type chickens. Br Poult Sci 45:355-366.

Lee KW, Lee SK, Lee BD 2006 Aspergillus oryzae as probiotic in poultry - A review. Int J Poult Sci 5:01-03.

Mountzouris KC, Tsirtsikos P, Kalamara E, Nitsch S, Schatzmayr G, Fegeros K 2007 Evaluation of the efficacy of a probiotic containing Lactobacillus, Bifidobacterium, Enterococcus, and Pediococcus strains in promoting broiler performance and modulating cecal microflora composition and metabolic activities. Poultry Sci 86:309-317.

Maiolino R, Fioretti A, Menna LF, Meo C 1992 Research on the efficiency of probiotics in diets for broiler chickens. Nutr Abstr Rev Ser B 62:482.

Midilli M, Alp M, Kocabağlı N, Muğlalı ÖH, Turan N, Yılmaz H, Çakır S 2008 Effects of dietary probiotic and prebiotic supplementation on growth performance and serum IgG concentration of broilers. South African J Anim Sci 38:22-27.

Mohan B, Kadvel R, Natarajan A, Baskaran M 1996 Effect of probiotic supplementation on growth, nitrogen utilization and serum cholesterol in broilers. Br Poult Sci 36: 395-401.

NRC 1994 Nutrient Requirements of Poultry. 9th rev. ed. Natl. Acad. Sci., Washington, DC.

Patterson JA, Burholder KM 2003 Application of probiotics and prebiotics in poultry production. Poultry Sci 82:627631.

Pelicia K, Mendes AA, Saldanha ES, Piazzolante C, Takahashi S 2004 Probiotic and prebiotic utilization in diets for free-range broiler chickens. Br J Poult Sci 92:99-104.

Ratcliff J 2000 Antibiotic bans-a European perspective. Proceedings of the $47^{\text {th }}$ Maryland Nutrition Conference on Food Manufatures, March 22-24, Univ. Maryland, Baltimore, 135-152.

Saarchit T, Sullivan TW 1990 Influence of a dried Bacillus subtilis culture and antibiotics on performance and intestinal microflora in turkeys. Poultry Sci 69:1966-1973.

SAS Institute 1998 SAS/STAT User's Guide. SAS Institute Inc, Cary, NC, USA.

Steel RGD, Torrie JH 1980 Analysis of Covariance. Principles and Procedures of Statistics: A Biometrical Approach. McGraw-Hill, New York. pp. 401-437.

Teo AY, Tan HM 2007 Evaluation of the performance and intestinal gut microflora of broilers fed on corn-soy diets supplemented with Bacillus subtilis PB6 (CloSTAT). J Appl Poult Res 16:296-303.

Thitaram, SN, Chung CH, Day DF, Hinton A, Bailey JS, Siragusa GR 2005 Isomaltooligosaccharide increases cecal Bifidobacterium population in young broiler chicken. Poultry Sci 84:998-1003.

Toghyani M, Toghyani M, Tabeidian SA 2011 Effect of probiotic and prebiotic as antibiotic growth promoter substitutions on productive and carcass traits of broiler chicks. International Conference on Food Engineering and Biotechnology IPCBEE vol. 9 IACSIT Press. Singapoore.

Tortuero F 1973 Influence of the implantation of Lactobacillus acidophilus in chicks on the growth, feed conversion, malabsorption of fats syndrome and intestinal flora. Poultry Sci 52:197-203.

Trafalska E, Grzybowska K 2004 Probiotics-An alternative for antibiotics? Wiad Lek 57:491-498.

Waldroup PW, Fritts CA, Fengland Y 2003 Utilization of Bio-Mos ${ }^{\circledR}$ mannan oligosaccharide and Bioplex ${ }^{\circledR}$ copper in broiler diets. Int J Poult Sci 2:44-52.

Watkins BA, Kratzer FH 1984 Drinking water treatment with commercial preparation of a concentrated Lactobacillus culture for broiler chickens. Poultry Sci 63:1671-1673.

Yalcinkayal H, Gungori T, Mafialani M, Erdem E 2008 Mannan oligosaccharides (MOS) from Saccharomyces cerevisiae in broilers: Effects on performance and blood biochemistry. Turk J Vet Anim Sci 32:43-48. 
Yoon C, Na CH, Park JH, Han SK, Nam YM, Kwon JY 2004 Effect of feeding multiprobiotics on performance and fecal noxious gas emission in broiler chicks. Korean J Poult Sci 31:229-235.
Ziggers D 2000 Tos, a new probiotic derived from whey. Anim Feed Sci Technol 5:34-36.

(received: 2012. 8. 22, revised: 2012. 11. 22, accepted: 2012. 12. 3) 